\title{
Migration of Ingested Fish Bone from Upper Aerodigestive Tract to the Skin of the Neck
}

\author{
Mukulika Saha, ${ }^{1}$ Amit Chakrabarti, ${ }^{1}$ Amit Bikram Maiti, ${ }^{1}$ Satadal Mandal ${ }^{1}$
}

\section{Introduction}

\section{ABSTRACT}

Ingested foreign bodies commonly get impacted in the upper aero digestive tract, but only a few of these foreign bodies have perforated the oesophagus and an even smaller number of these have migrated extraluminally.

\section{Case report}

A 43 year old male patient presented with history of accidental ingestion of fish bone (F.B) 3 weeks back. On examination a sharp pointed swelling was seen over right side of neck and on palpation a pointed object was felt beneath the intact skin. Digital $X$-ray, ultrasonography of the neck and CT scan neck showed a linear obliquely placed foreign body on right side of neck at the level of thyroid gland. The foreign body was easily removed by an incision over the skin and was confirmed to be a fish bone. Discussion

Horizontally oriented foreign bodies are more likely to penetrate the lumen of a hollow viscus. The muscular contraction of the neck might account for this unusual event to some extent, one possible factor being that the presence of the foreign body in the soft tissue might have led to inflammation and oedema, which made the texture of the surrounding tissue loose and lax; a sort of gel-sol interconversion.

$\underline{\text { Kevwords }}$

Foreign Bodies; Neck; Esophagus; Punctures; Tomography, X-Ray Computed; X-Ray

I $\mathrm{n}$ the literature, various cases have been described where foreign bodies have been ingested and have lodged in the upper aerodigestive tract, but only a few of these foreign bodies have perforated the oesophagus and an even smaller number of these have migrated extraluminally. ${ }^{1}$ Fish bones constitute more than $85 \%$ of all foreign bodies. ${ }^{2}$ There have been rare cases reported, in which the foreign body actually exits through a puncture wound in the skin of the neck. ${ }^{3}$ Here we report a case of foreign body near extrusion through the skin.

The specific nature of the symptoms of course is very helpful in localizing the site of the foreign body. Endoscopic findings of ulceration, oedema, and laceration should lead to the suspicion of migration. ${ }^{4}$ If untreated, these migratory foreign bodies may result in life threatening suppurative or vascular complications like deep neck space infection, mediastinitis, lung abscess, oesophageal-carotid artery fistula, retropharyngeal abscess, vascular complications and thyroid abscess. ${ }^{5}$

\section{Case Report}

A 43 years old male patient attended the Otolaryngology Out Patient Department with history of accidental ingestion of fish bone (FB) 3 weeks back. He had an episode of pain and dysphagia for few hours only. After 20 days of asymptomatic interval he suddenly felt a sharp pointed swelling on right side of his neck (Fig.1). On examination, a sharp pointed swelling was seen over right side of neck and on palpation a pointed object was felt beneath the intact skin. The swelling was nontender, local temparature was not raised. He did not have any pain, fever, dysphagia, respiratory distress, nausea, vomiting. Oral cavity and oropharynx were normal. No abnormality was found on indirect laryngoscopy.

1 - Department of ENT, Midnapur Medical College,
Midnapur, West Bengal
Corresponding author:
$\begin{aligned} & \text { Dr Mukulika Saha } \\ & \text { email: mukulikasaha61@gmail.com }\end{aligned}$

1 - Department of ENT, Midnapur Medical College,

Corresponding author:

email: mukulikasaha61@gmail.com 
Digital X-ray showed a sharp linear pointed radio opaque foreign body towards the skin (Fig.2). Ultrasonography of the neck showed a linear obliquely placed foreign body on right side of neck at the level of thyroid gland, measuring approximately $2.6 \mathrm{~cm}$. Jugular vessels on both sides were normal. (Fig. 3).

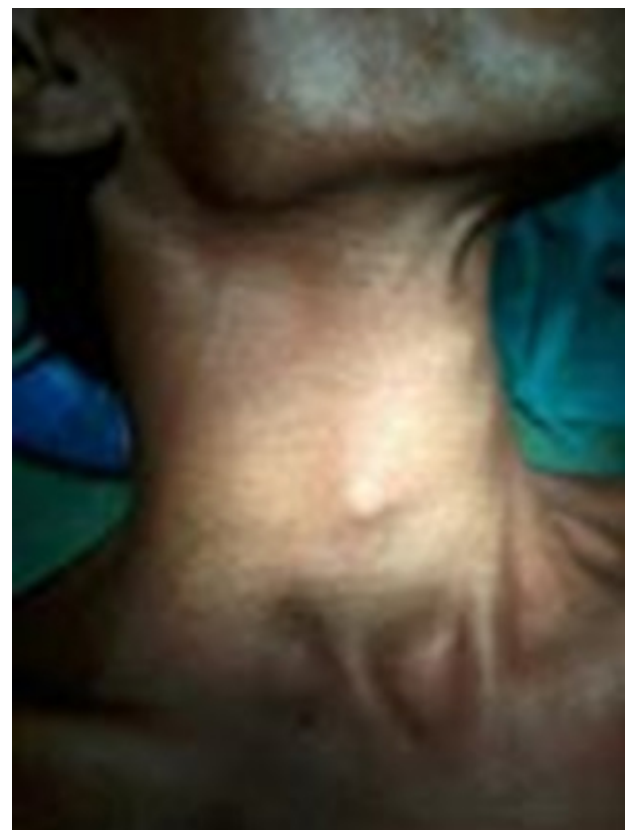

Fig. 1 Swelling on the right side of the neck

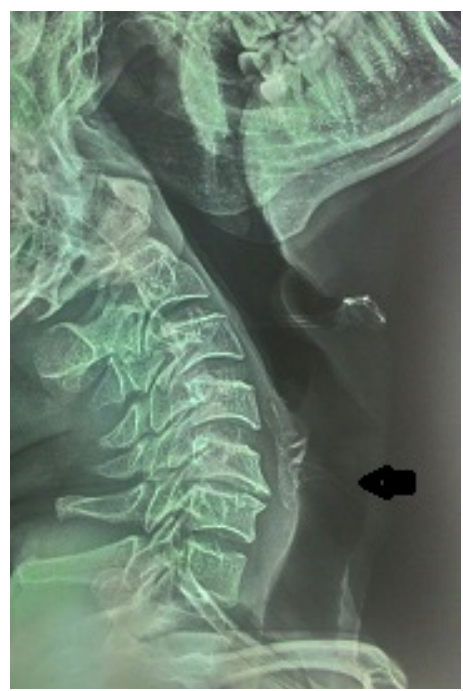

Fig. 2 X-ray soft tissue neck (lateral view) showing radiopaque foreign body
A noncontrast computed tomography of neck showed the foreign body tenting the skin (Fig. 4). Vital structures of neck were not involved. The patient was admitted and prepared for removal under local anaesthesia. The foreign body was easily removed by an incision over the skin \& was confirmed to be a fish bone (Fig. 5).

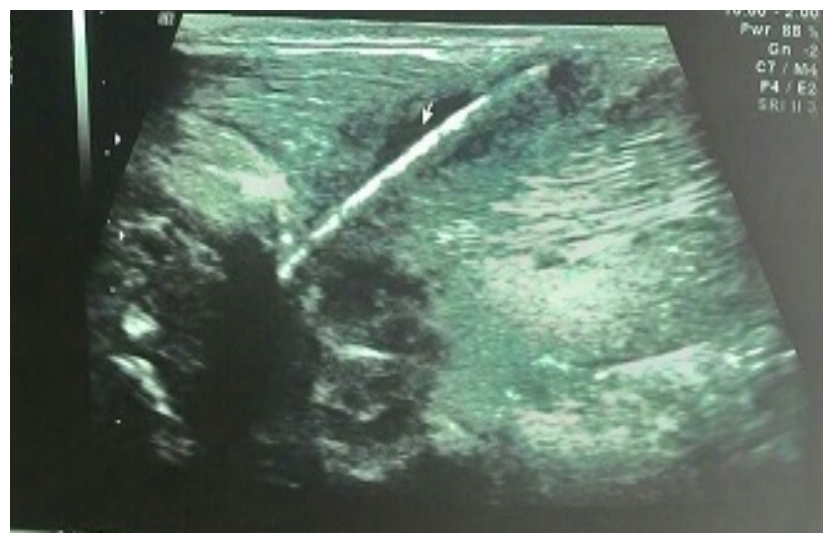

Fig. 3 Ultrasonography of the neck showing a linear foreign body

\section{Discussion}

Fish bones account for the commonest ingested foreign bodies in eastern and coastal regions of India. A majority of ingested foreign bodies pass through the gastrointestinal tract uneventfully. Rest of the foreign bodies are usually found intraluminally most commonly at tonsils, base of the tongue or the vallecula and can be easily removed. In about $5 \%$ of the cases, the foreign body becomes lodged at the cricopharyngeal region or at one of the other constrictions along the oesophagus, requiring a rigid oesophagoscopy under general anaesthesia for its removal.

Migration is said to have occurred in the event of a negative rigid endoscopy and the presence of a foreign body on radiography. ${ }^{2}$ In the Remsen et al. series, 321 cases of penetrating foreign bodies were reviewed from literature and only 43 were found extraluminally. ${ }^{5}$ They found that the sharper the foreign body the higher the risk of penetration. Chee and Sethi reported a series of 24 migrated foreign bodies in the neck. All of the foreign bodies in their series were sharp and linear. ${ }^{2}$

The risk of penetration is also influenced by 


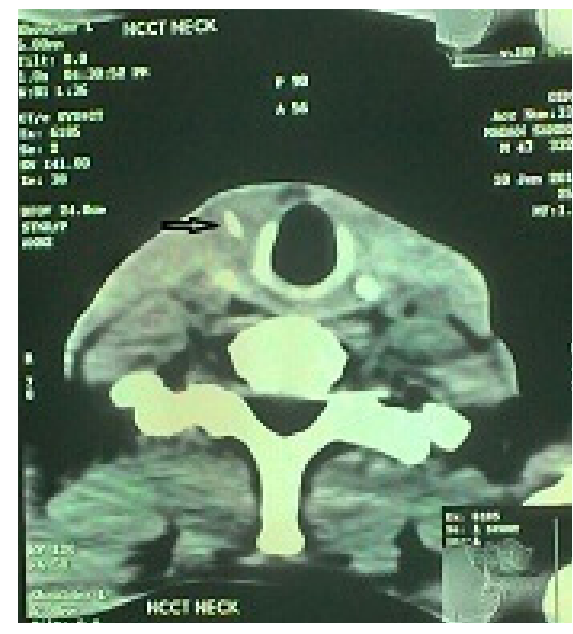

Fig. 4 Noncontrast CT scan neck showing foreign body

the orientation of the foreign body. Horizontally oriented foreign bodies are more likely to penetrate. Extraluminally migrated fish bones have been reported to cause neck abscesses. This happens due to the contractions of hypopharynx during deglutition which forces the fish bone to penetrate the wall. Thyroid gland penetration by a migrating foreign body with subsequent abscess of thyroid lobe has been reported for which thyroid lobectomy was done. ${ }^{6}$

Pathophysiology and biomechanical process by which a sharp fish bone has penetrated the walls of the pharynx or oesophagus and found its way towards the cutaneous surface, almost in a straight line along the axial plane of the neck, is difficult to ascertain. The muscular contraction of the neck might account for this unusual event to some extent, but even they might not be sufficient because as far as the strap muscles of the neck are concerned, their line of action is perpendicular to the direction of the movement of the fish bone. Theoretically then, no component of force vector should be available. However, the contractions of the constrictor muscles of the pharynx and circular muscle of the oesophagus might have produced the outward force acting on the surrounding soft tissue, thereby pushing the foreign body slowly towards the periphery.

One possible factor is that the presence of the foreign

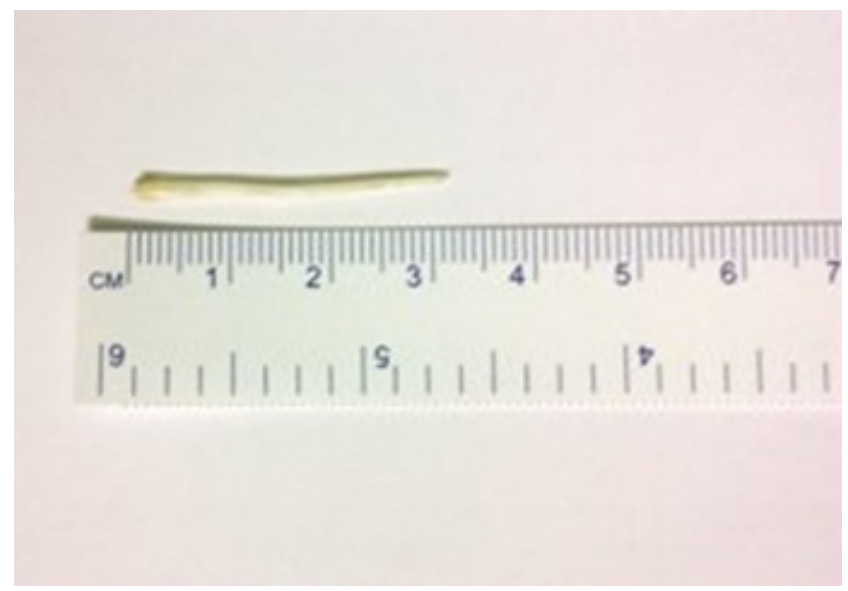

Fig. 5 The fish bone (after removal)

body in the soft tissue might have led to inflammation and oedema, which made the texture of the surrounding tissue loose and lax; a sort of gel-sol interconversion. Next, the complex muscular movement of the neck, as previously mentioned, might have generated some expanding pressure and directed the sharp foreign body to move outward slowly toward the skin surface. ${ }^{7}$

\section{References}

1. Sreetharan SS, Prepageran N, Satwant S. Unusual migratory foreign body in the neck. Singapore Med J 2004; 45: 487-8

2. Chee LW, Sethi DS. Diagnostic and therapeutic approach to migrating foreign bodies. Ann Otol Rhinol Laryngol 1999; 108: 177-80

3. Sethi DS, Stanley RE. Migrating foreign bodies in the upper digestive tract, Ann Acad Med Singapore 1992;21: 390-3.

4. Vadhera R, Gulati SP, Garg A, Goyal R, Ghai A. Extraluminal hypopharyngeal foreign body. Indian J Otolaryngol Head Neck Surg 2009; 61: 76-8

5. Remsen K, Lawson $\mathrm{W}$, Biller HF and Som ML. Unusual presentations of penetrating foreign bodies of the upper aerodigestive tract. Ann Otol Rhinol Laryngol (Suppl) 1983; 105: 32-44

6. Goh YH, Tan NG. Penetrating oesophageal foreign bodies in the thyroid gland. J Laryngol Otol 1999; 113: 769-71

7. Sinha R, Sen I, Saha J, Mukherjee A, Guha R. Migration of fish bone from upper aerodigestive tract to the skin of the neck: A case report. Ear Nose Throat Journal 2013; 92:E15 